\title{
Clinical and Radiological Profile of Pulmonary Hydatid Cysts
}

\author{
Nahid ZAGHBA, Khadija Fahmi ${ }^{*}$, Hanane Benjelloun, Najiba Yassine
}

Service of Respiratory Diseases, Hospital CHU Ibn Rochd, 1 Rue Des Hôpitaux, Casablanca 20000, Morocco

DOI: $10.36347 /$ sasjm.2020.v06i05.002

| Received: 02.05.2020 | Accepted: 09.05.2020 | Published: 12.05.2020

*Corresponding author: Khadija Fahmi

\section{Abstract}

Original Research Article

Introduction: Pulmonary hydatid cyst (KHP) is a major health problem, both in frequency and severity. Methods: To determine the epidemiological profile, the clinical and radiological aspects of KHP, we conducted a retrospective descriptive study of 184 cases identified in the respiratory diseases department of the Ibn Rochd Hospital in Casablanca between 2005 and 2019. Results: 93 women and 91 men. The average age was 38.6 years. The revealing signs were dominated by chest pain $(84 \%)$. The diagnosis of pulmonary hydatidosis was based on imaging and hydatid serology. Thoracic CT was performed in $94 \%$ of cases. Bronchoscopy had visualized watery membranes in $22.3 \%$ of cases. Hydatic cyst was unique in $58 \%$ of cases, associated with liver damage in $19 \%$ of cases, heart damage and pulmonary artery in $1.6 \%$ of cases. Treatment was surgical in $70.6 \%$ of cases. The progression was good in $83 \%$ of cases. Conclusion: Hydatid disease is characterized by clinical polymorphism. Chest X-ray is often sufficient to make the diagnosis, while chest CT is still the choice for complicated cysts.

Keywords: Clinical aspects; epidemiology; pulmonary hydatid cyst; imaging.

Copyright @ 2020: This is an open-access article distributed under the terms of the Creative Commons Attribution license which permits unrestricted use, distribution, and reproduction in any medium for non-commercial use (NonCommercial, or CC-BY-NC) provided the original author and source are credited.

\section{INTRODUCTION}

Pulmonary hydatidosis is an anthropozoonosis due to the development of the larval form of Taenia Echinococcus Granulosus in humans. It is a cosmopolitan infection that plagues sheep and cattle farming areas, especially around the Mediterranean. Lung involvement represents $20-45 \%$ of all water locations [1] and is the second location after liver involvement. The positive diagnosis of pulmonary hydatid cysts (KHP) is based on epidemiological, clinical, biological and radiological arguments.

\section{Methods}

This is a retrospective descriptive study of 184 cases of pulmonary hydatid cysts collected in the respiratory diseases department of the Ibn Rochd Hospital Hospital in Casablanca over a period of 14 years, from January 2005 to December 2019. The data were processed by Excel.

\section{RESUlTS}

These were 93 women and 91 men, ranging in age from 14 to 75 with an average age of 38.6. The majority of our patients $(65 \%)$ were under the age of 35 . The majority of the patients were rural (129 cases or $70 \%$ ). Fifty-eight patients or $31.5 \%$ had contact with dogs. For the profession seven patients were butchers, nine were shepherds, and five were concrete sellers. A history of hydatid cyst surgery was found in eight cases including four pulmonary and four hepatic. The average time between onset of symptoms and hospitalization was two months. Clinical symptomatology consisted of chest pain in 155 cases (84\%), cough in 147 cases $(80 \%)$, hemoptysis in 67 cases $(36 \%)$, hydatidoptysis in 26 cases $(14.1 \%)$ and syncope in two cases $(1 \%)$.

Five patients were asymptomatic and the discovery was accidental during a preoperative assessment in seven patients and during a preemployment assessment in five cases. General condition was maintained in $81 \%$ of cases. The pleuropulmonary examination was normal in 129 cases $(70 \%)$ and found submatity in 36 cases $(19.5 \%)$, condensation syndrome in seven cases $(3.8 \%)$ and fluid and mixed effusion syndrome in six cases each (3\%). The abdominal examination had objectified hepatomegaly in ten cases $(5.4 \%)$ and splenomegaly in six cases $(3.2 \%)$. thoracic radiography had objectified variable aspects (opacity at regular edges in $53.2 \%$ of cases, hydroaeric waved level image in $20.6 \%$ of cases, balloon release appearance in $9.2 \%$ of cases fig. 1, pleural opacity in $3 \%$ of cases, and rattle image in $1.6 \%$ of cases), these aspects are summarized in Table I. 
Chest computed tomography was performed in 173 patients (94\%) and had different scannographic aspects (a very limited fluid mass in $52 \%$ of cases, a hydroaeric image in $13.2 \%$ of cases, a balloon release aspect in $9.8 \%$ of cases fig 2, a hydropneumothorax in $2.8 \%$ of cases, and a rattle image in $2.3 \%$ of cases), these aspects are illustrated in Table II. It also made it possible to individualize hydatid cysts associated in particular hepatic in $19 \%$ of cases, splenic in $6.5 \%$ of cases, mediastinal in $3 \%$ of cases. Cardiac and pulmonary artery involvement were noted in $1.6 \%$ of cases and pericardial, pleural (fig. 3), diaphragmatic (fig. 4) and aortic involvement in $0.5 \%$ of cases each.

Hydatid cyst was unique in 108 cases $(58 \%)$, bifocal in 36 cases $(19.5 \%)$, and multiple in 40 cases $(21.7 \%)$. Localization in the right lung was most common in 126 cases $(68 \%)$. Hydatid cyst was healthy in 89 cases $(48.3 \%)$, cracked in 27 cases $(14.6 \%)$, and broken in 68 cases $(36.9 \%)$. Abdominal ultrasound performed systematically in all our patients, had visualized a hepatic hydatid cyst associated in 35 cases (19\%) and splenic in 12 cases $(6.5 \%)$. The cardiac ultrasound showed an objective biauricular cyst (left and right atrium) multi-vesicular, associated with pericardial and pulmonary artery cysts in one case, ventricular cyst and pulmonary artery in two cases. THE thoracic MRI performed in two patients confirmed lung, arterial and cardiac localization of cysts. Flexible bronchoscopy was performed in all our patients, it objectified watery membranes in 41 cases $(22.3 \%)$ and the presence of scolex in bronchial aspiration fluid in nine cases $(4.8 \%)$. Hydatid serology was positive in 99 cases $(55 \%)$. Treatment was surgical in 130 cases $(70.6 \%)$, associated with medical treatment in 7 cases $(5.3 \%)$. Medical treatment alone was indicated in 54 inoperable cases (40 multiple hydatidose cases, one pulmonary artery site case, and 13 inoperable patient cases). It was based on Albendazole orally at the rate of $10-15 \mathrm{mg} / \mathrm{kg} / \mathrm{d}$ in two doses with cycles of 28 days separated by two weeks interval with an average number of 7 therapeutic cycles. The surgical treatment was done by conservative or/and radical methods, the conservative methods being the kystectomy in 65 cases, the aspiration puncture and perikystectomy in 28 cases. Segmentectomy in 28 cases and lobectomy in nine cases. Video-assisted thoracic surgery (VATS) is performed through a mini-thoracotomy was the most commonly used method in 111 cases. Surgical removal of cardiac and arterial cysts was performed under extracorporeal circulation (ECC) in two cases and an aortic cyst was discovered intraoperative in one case. Prevention measures and education were systematic in all of our patients. The evolution was good in 154 cases $(83.6 \%)$, a recidivism was noted in five cases $(2.7 \%)$ and three deaths $(1.6 \%)$ were reported as a result of a post PH chronic hydatic embolism. Twenty-two patients $(11.9 \%)$ were lost.

Table-I: Radiological aspects of KHP

\begin{tabular}{|l|l|l|}
\hline Radiological aspect & Number of patients & \% \\
\hline Homogeneous opacity with regular edges & 98 & 53,2 \\
\hline Hydro-aeric image with irregular level & 38 & 20,6 \\
\hline Hydro-aeric image with regular level & 12 & 6,5 \\
\hline Balloon release aspect & 17 & 9,2 \\
\hline Inhomogeneous opacity with blurred edges & 9 & 4,8 \\
\hline Opacity of pleural type & 6 & 3 \\
\hline Image in fungal ball & 3 & 1,6 \\
\hline Cavity image & 1 & 0,5 \\
\hline
\end{tabular}

Table-II: Scan aspects of KHP

\begin{tabular}{|l|l|l|}
\hline Scannographic aspects & Number of patients & \% \\
\hline Well limited fluid mass & 90 & 52 \\
\hline Hydro-aeric image with corrugated level & 23 & 13,2 \\
\hline Hydro-aeric image with regular level & 7 & 4 \\
\hline Balloon release aspect & 17 & 9,8 \\
\hline Multi vesicular appearance & 12 & 6,9 \\
\hline Pseudotumoral appearance & 6 & 3,4 \\
\hline Crimp aspect & 5 & 2,8 \\
\hline Hydropneumothorax & 5 & 2,8 \\
\hline Image in fungal ball & 4 & 2,3 \\
\hline Cavity image with membrane retention & 1 & 0,5 \\
\hline
\end{tabular}


Table-III: Comparative table of clinical signs by authors

\begin{tabular}{|c|c|c|c|c|}
\hline & \multicolumn{2}{|c|}{ Racil [23]. N \% } & \multicolumn{2}{|c|}{ Our series N \% } \\
\hline Cough & 41 & 78,8 & 147 & 80 \\
\hline Chest pain & 28 & 53,8 & 155 & 84 \\
\hline Hemoptysis & 37 & 71,2 & 67 & 36 \\
\hline Hydatidoptysie & 22 & 42,3 & 26 & 14,2 \\
\hline Syncope & - & - & 2 & 0,1 \\
\hline Asymptomatic & - & - & 5 & 2,7 \\
\hline
\end{tabular}

Table-IV: Different scan aspects by authors

\begin{tabular}{|l|ll|l|}
\hline & \multicolumn{2}{|l|}{ Racil [23]. (n : 53) N \% } & Notre série (n : 173)N\% \\
\hline Round or oval image, sharp boundaries & \multicolumn{2}{|c|}{-} & 90 \\
\hline Hydro-aeric image regular water level & 8 & 12,5 & 7 \\
\hline Hydro-aeric image water level corrugated & 15 & 23,4 & 23 \\
\hline Image in fungal ball & 6 & 9,4 & 4 \\
\hline Pseudotumoral appearance & 19 & 27,7 & 6 \\
\hline Balloon release aspect & 3 & 4,7 & 17 \\
\hline Hydropneumoyhorax & 3 & 10,9 & 5 \\
\hline Cavitary Image with membrane retention & 4 & 6,2 & 1 \\
\hline
\end{tabular}

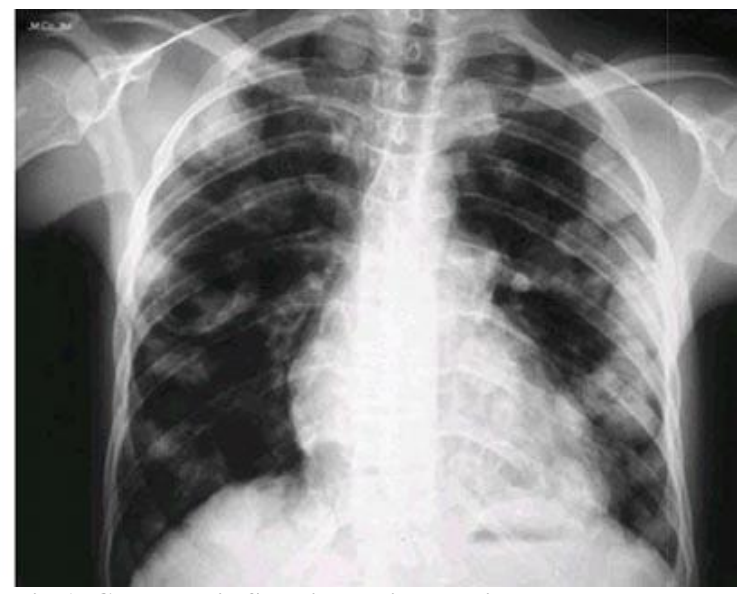

Fig-1: Chest Radio Showing United Nations Balloon Drop Appearance

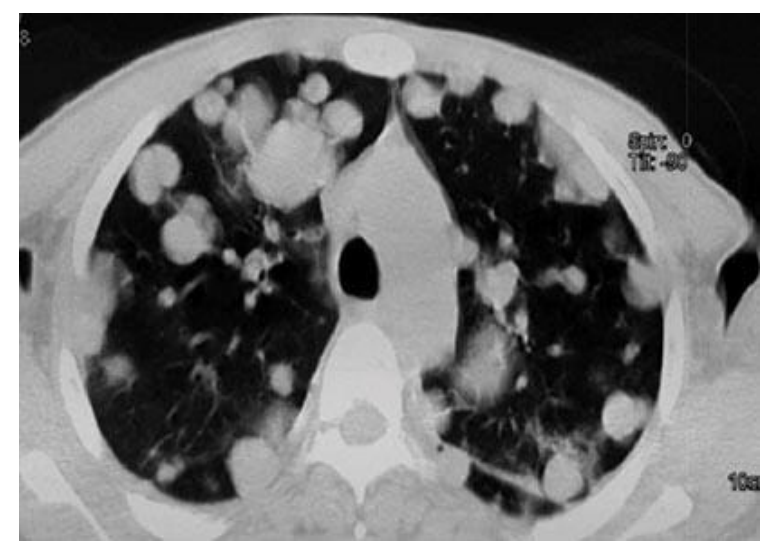

Fig-2: Thoracic CT of multiple pulmonary hydatidosis

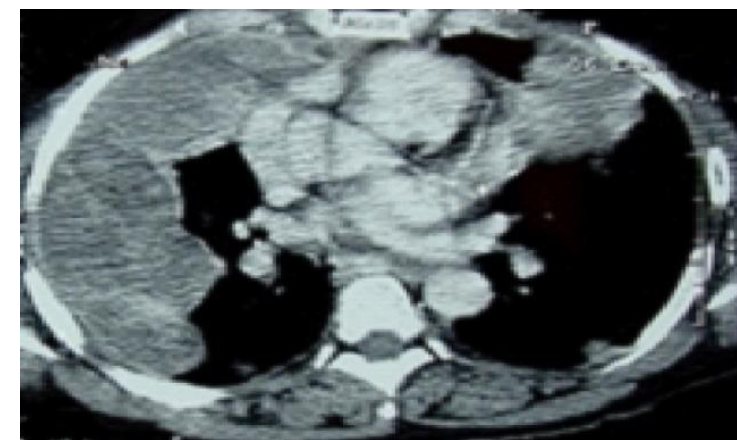

Fig-3: Thoracic CT with right pleural and pulmonary fluid cyst

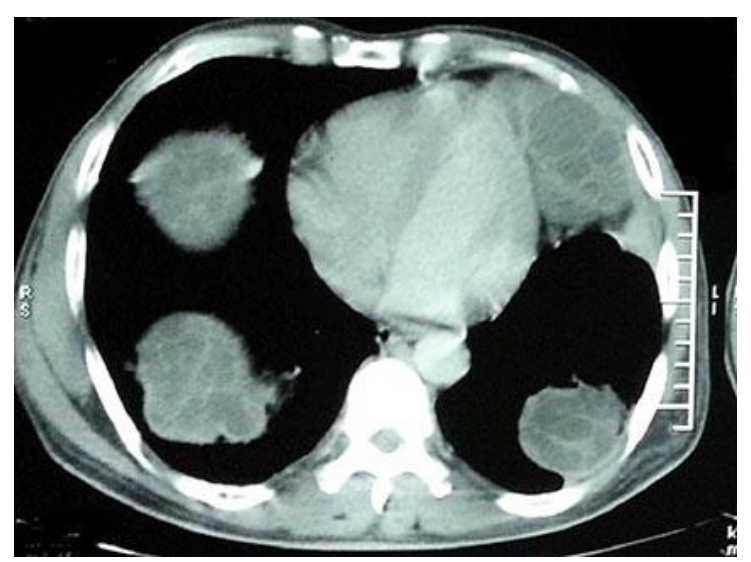

Fig-4: Thoracic CT with pulmonary and diaphragmatic hydatid cysts 


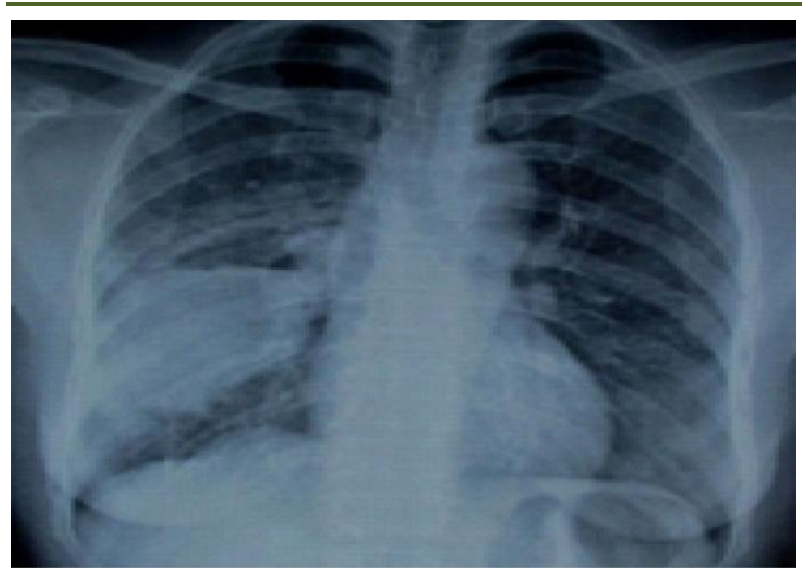

Fig-5: Radiothorax objectifying a hydro-aeric image with irregular level

\section{DISCUSSION}

Hydatidosis, or hydatid disease, is a cosmopolitan parasitosis that plagues the state endemic. It is responsible for accidental contamination of humans by a parasite metacestode of which the final host is the dog and the intermediate host is a herbivor. In Europe, hydatidosis is much rarer; it usually affects emigrants from endemic areas [2]. The results of the studies indicate that its prevalence in the areas between $1 \%$ and $10 \%$ [28]. The highest prevalence is found in the temperate zone countries including the countries of the Mediterranean region, the centre and the countries of Eastern Europe, central Asia, China, Australia, and some Sub-Saharan Africa and South America [3,4]. In Morocco, it represents a real public health problem due to its chronic nature and complications According to the Interdepartmental Counter-Terrorism Committee Hydatidosis/Echinococcosis from 2007 in Morocco [5], the frequency of liver damage is $50-70 \%$ of cases followed by lung damage, which remains the second location of predilection, which is $25-40 \%$ of cases. Bone localization is $0.5-2.5 \%$ and the heart level is 0.02 to $2 \%$. Multiple contributing factors, environmental, socio-cultural and socio-economic, are at the origin of this hyper-endemicity. In 2011, a prevalence of 7.76 per 100,000 inhabitants was recorded in Morocco [6] with high frequency in some areas of the country, especially the West, the Middle Atlas and Eastern Morocco [7]. The rural origin of the patients is predominant in our context, found in $70 \%$ of patients. This result was confirmed by other authors [8]. A male predominance was noted in most body studies[9], while there was had no sex difference in our series. Hydatidosis is the prerogative of the adult, it is rare in children and the elderly. The average age of our patients was 38.6 years, this joins the AMOUIAN series [10]. The pulmonary localization of the hydatic cyst 2 nd rank after liver localization. Indeed After intestinal passage, the larva reaches liver then lung with possibility of passage through the systemic circulation giving localizations sometimes rare and unusual throughout the body [11]. During its evolution in the lung, the fluid cyst gradually increases in volume and between in contact with the bronchi causing erosion of their walls and preening to some complications such as suppuration, endobronchial rupture, inflammation and pulmonary calcification. The clinical manifestations of the pulmonary hydatid cyst are diverse and depend on its size, location and especially it's complicated or not. Small healthy pulmonary cysts are often asymptomatic from radiological discovery often incidental [12]. Unlike the voluminous cyst, which is accompanied by non-specific clinical manifestations such as chest pain, dry cough and hemoptysis. Ruptured pulmonary hydatid cysts in the bronchi are most often manifested by hydatidoptysis, which is the only specific sign of KHP, or by hemoptysis or repetitive bronchial suppurations $[13,14]$. In case of ruptured cyst in the pleura, brutal pain and dyspnea are the revealing symptoms. Although exceptional, some allergic manifestations may exist, such as a state of anaphylactic shock noted in a case in our series, in a patient who had a ruptured KHP in the pleura.

Clinical examination of the rib cage may be normal or reveal bronchial rails, condensation syndrome, cavity syndrome or fluid or mixed effusion syndrome when the cyst is broken in the pleura or enlarged. All these clinical aspects were noted in our series. Hydatitoptysis, the only specific sign which corresponds to the discharge through the mouth and/or the nose of a clear liquid with a salty taste in which membrane debris is found, was objectified in $14.1 \%$ of cases, while the discovery of the hydatid cyst was fortuitous in five cases. According to the authors, Table III summarizes the different functional signs represented mainly by cough, chest pain, haemoptysis and hydatidoptysis. Other associated locations, especially hepatic, must be systematically searched. Khps most often sit at the level of the right lung, preferably at the level of the lower lobes and can be bilateral in $20 \%$ of cases and multiple in $30 \%$ of cases [15]. In our series the KHP was in right seat in $68 \%$ of the cases, they were multiple in $21.7 \%$ of the cases, so our results join those of the literature. Imaging plays an important role in the diagnosis of KHP. Different radiological aspects may exist and vary depending on the evolutionary stage of KHP and complications. On thoracic radiography, a healthy hydatid cyst is manifested by a round or oval opacity with clear contours, of water density, realizing an aspect «cannonball», this is the most frequent aspect, found in 52.2 to $78 \%$ in the literature $[16,17]$. In our study, this aspect is noted in $52 \%$ of cases. When cracked, it is manifested by a round image surmounted by the classic gaseous meniscus realizing the pneumokyst image. In case of ruptured cyst in the bronchi, the aspect found is a hydro-aeric image with regular or irregular level (fig. 5) corresponding to the typical floating membrane image performing the sign of Nenuphar which is a pathognomonic sign noted in 16-30\% of complicated KHP cases $[18,19]$. It was found in $17.2 \%$ of cases in our series. More rarely we can observe the double arc image of Ivassinevitch or bridge opacity which 
corresponds to the endocyst partially detached above the liquidian level. In case of vomited cyst, the radiological aspect varies according to the degree of evacuation of the cyst; one can find a cockade image that presents itself as a round opacity with blurred boundaries, surrounded by fine ring clarity or an image of a paddled membrane or dry membrane retention [19].

Thoracic ultrasound is currently considered a complement to thoracic radiography in the exploration of pulmonary hydatidosis [18]. In addition, the latter lack sensitivity and remains relatively limited in employment. The limits of thoracic ultrasound are good indications for thoracic computed tomography in hydatic pathology, although it is reserved only for complicated and atypical forms. It confirms the cystic nature of pulmonary opacity and can count lesions and look for other possible chest locations that may go unnoticed by standard radiography. Different scannologic aspects Table IV, can exist and depend on the state of the cyst. A healthy cyst is most often presented as a single fluid mass that is sometimes voluminous, homogeneous, well-limited, surrounded by a smooth and even wall. When the cysts are multiple, they achieve a «balloon release» aspect noted in 9.8\% of cases.

In case of a ruptured cyst in the bronchi, DB Lewall and SJ Mc Corkell [20], allowed to individualize $6 \mathrm{CT}$ stages according to the evolution of the cyst:

Stage I or "chestnut ring" appearance: is due to the entry of a minimal amount of air between the endocyst and the pericyst, without detachment of the endocyst.

Stage II or aspect of "crescent" or "inverted crescent": corresponds to partial detachment of the endocyst.

Stage III or appearance of "trapped sightings" and "honeycomb": the result of a total detachment of the endocyst without evacuation of the liquid contents. The appearance of 'trapped light' is defined by the presence of small air bubbles trapped between the folds of the endocyst detached within the fluid content. When the bubbles are very numerous, they realize the «honeycomb» aspect.

Stage IV: presents as hydro-aeric images with regular or irregular level in connection with a detachment of the endocyst and partial evacuation of the fluid content of the cyst realizing either a «double arc» aspect where the endocyst is partially collared, either an aspect of the "water lily" or the endocyst is totally sticky and floats on the liquid content, or the "piggyback" aspect where the endocyst is totally detached and remains immersed in the declive hydatic fluid. This aspect is noted in $2.8 \%$ of cases in our study. The latter three aspects are pathognomonic of KHP

Stage V: aspect of dry retention, it is the result of a complete evacuation of the hydatid fluid and the retraction of the endocyst realizing an aspect of «ball of wool» or «bell» or even a pseudotumoral aspect. The latter two aspects were noted in $2.3 \%$ and $3.4 \%$ respectively in our series.

Stage VI or sequellary aspect, it is the result of a complete elimination of the contents of the KHP leaving a thin-walled or thick-walled aerated cavity or a nonseptal linear dense image. The biological diagnosis of hydatidosis is based on hydatid serology which maintains an interest in post-therapeutic monitoring and whose sensitivity increases in case of complicated and hepatic hydatid cysts [21,22]. Qualitative hydatid serology (immunoelectrophoresis, electrosyneresis), and quantitative serology (direct hemagglutination, indirect immunofluorescence, ELISA), makes it possible to guide the diagnosis in 40 to $65 \%$ of lung locations [29]. In our series, the hydatic serology was positive and guided the diagnosis in $55 \%$ of cases while it was negative in $45 \%$ of cases. This can be explained by the frequency of healthy and intact cysts in our patients.

Flexible bronchoscopy has a diagnostic interest when it visualizes pearly white membranes in bronchial light and individualizes scolex in bronchial aspiration fluid. These indications remain limited and are carried out especially in case of diagnostic doubt, in case of hemoptysis or to eliminate neoplasia [23]. In our context, it was required by surgeons before any surgery and was performed in all our patients. It objectified watery membranes in 41 cases $(22.3 \%)$ and scolex in bronchial aspiration fluid in nine cases $(4.8 \%)$.

Multiple hydatidosis is rare and its frequency varies between 11 and 30\% [23]. It can be primitive following a massive and iterative infestation, or secondary to metastatic dissemination following an opening of a primitive $\mathrm{KH}$ in the venous system with migration of cysts to the right heart and pulmonary artery leading to hydatic emboli [23]. Bronchogenic spread is possible but exceptional. In case of multiple pulmonary hydatidosis, the search for other cardiac locations is necessary, hence the interest of a systematic echocardiography. Cardiac localization is rare [30, 31] even in endemic countries. It can be sub-endocardial, sub-epicardial, epicardopericardial, or intracardial (VD, $\mathrm{VG}, \mathrm{OD}, \mathrm{OG})$, it is characterized by the severity of its spontaneous evolution and the frequency of its complications which are very often revealing. In our series, the echoheart objectified a biauricular cyst associated with pericardial and pulmonary artery cysts in one case and a ventricular cyst associated with a pulmonary artery cyst in two cases. Abdominal ultrasound is a systematic practice in the face of any 
suspicion of pulmonary hydatidosis, it makes it possible to search for possible intra-abdominal hydatical locations that may pose therapeutic problems of chronological order [24]. In our series this allowed to visualize a hepatic hydatid cyst associated in 35 cases $(19 \%)$ and splenic in 12 cases $(6.5 \%)$. Thoracic magnetic resonance imaging, on the other hand, has very limited indications in thoracic hydatidosis. It is especially useful in cases of mediastinal, spinal or thoracic parietal localization associated with lung involvement [24]. It remains efficient and allows analyzing vascular structures and detecting cardiac damage. It confirmed the lung, arterial and cardiac localization of the cysts in two patients. KHP can be complicated by cracking which is the first complication during the evolution of a cyst, which can lead to further dissemination, or rupture that follows cracking and can be done at the bronchial level, translating into hydatidoptysis, or in the pleural cavity performing a secondary pleural hydatidosis and its frequency varies from $2.4 \%$ to $10.4 \%$ according to the literature [25.26]. It was noted in $5.6 \%$ of the cases in our series, or at the pericardium performing a hydatid pericarditis. It can persist a residual sequellary cavity with risk of aspergillar grafting. Pachypleuritis can occur following a chronic inflammatory reaction of the pleura. Finally the recurrence is possible following an incomplete surgical treatment, a leak of liquid after rupture, or a reinfestation.

The treatment of choice for KHP is surgery. Medical treatment with Albendazole at a rate of 10-14 $\mathrm{mg} / \mathrm{kg}$ per day for a period of 3-6 months or in the form of 28-day cycles spaced 2 weeks apart [27] is indicated in multiple inoperable forms, in case of refusal of surgery or perioperative to reduce the risk of dissemination or relapses. In our series surgery was recommended in the majority of our patients, in 130 cases (70.6\%), while medical treatment was recommended in 54 patients $(29.3 \%)$.

The recidivism rate in the literature ranges from $0.5 \%$ to $11.3 \%$ [23]. In our series, it was $2.7 \%$, this can be explained by incomplete surgical removal or by the persistence of hydatid cysts of small sizes gone unnoticed. The prevention of this pathology called "Dirty Hand Disease" focuses on vermifugation of final hosts (dog and sheep), strengthening food control, improving slaughterhouse hygiene and public awareness campaigns.

\section{CONCLUSION}

Through our study, it turns out that hydatid disease remains a common pathology in our context, characterized by variable and aspecific clinical signs outside of hydatidoptysis. Thoracic X-ray and abdominal ultrasound are the first-line examinations for the diagnosis of hydatidosis, however the contribution of thoracic TDM remains essential to better specify the number, location and characteristics of these cysts.
Thoracic MRI and echoheart, on the other hand, are not systematic and their indications remain limited. The treatment of choice is surgery, and prevention remains the cornerstone in management.

\section{CONFLICTS OF INTEREST}

The authors do not declare any conflict of interest.

\section{REFERENCES}

1. Elbiaze M. [Thoracic hydatid cysts: news]. Rev Mal Respir. 2006;23(4 Pt 2):10S80-10S82.

2. Bouhaouala MH, Hendaoui L, Charfi MR, et al. Hydatidose thoracique, EMC. Elsevier Masson, Radiodiagnostic-coeur-poumon; 2007.

3. Derfoufi O, Akwa EN, Elmaataoui A, Profil épidémiologique de l'hydatidose au Maroc de 1980 à 2008. Ann. Biol. Clin. 2012; 70(4) : 457-61.

4. Bastid C. Kyste hydatique du foie. EMCHépatologie. 2014;9(4):1-13.

5. Comité interministériel de lutte contre l'hydatidose / echinococcose. Lutte contre l'hydatidose/echinococcose: guide des activités de lutte, 2007. Disponible sur internet: url:http://www.sante.gov.ma

6. El Majhad A, Lachhab A, Cherradi R. [The contribution of magnetic resonance imaging (MRI) in the diagnosis of cardiac hydatid cyst]. East Mediterr Health J Rev Santé Méditerranée Orient Al-Majallah Al-Ṣiḥhịyah Li-Sharq Al-Mutawassiṭ. 2011;17(12):996-1000.

7. Er Raji I. Kyste hydatique du poumon (A propos de 100 cas). Published Online First: 2009.http://toubkal.imist.ma/handle/123456789/80 38 (accessed 22 Sep2016).

8. Benchekroun A, Lachkar A, Soumana A. [Hydatid cyst of the kidney. Report of 45 cases]. Ann Urol. 1999;33(1):19-24.

9. Salih OK, Topcuoğlu MS, Celik SK. Surgical treatment of hydatid cysts of the lung: analysis of 405 patients. Can J Surg J Can Chir. 1998;41(2):131-5.

10. Amoueian S, Tayebi MN, Mohammadian RN. A retrospective study of 1759 cases of hydatid cyst in Mashad university hospitals. Published Online First.

11. Kabiri H, el Fakir Y, al Aziz S. Hydatid thymic cyst. A case report. Rev Pneumol Clin. 1999;55(6):399-402.

12. Kabiri E-H, Kabiri M, Atoini F. Surgical treatment of pulmonary hydatid cysts in childhood. Arch Pédiatrie Organe Off Sociéte Fr Pédiatrie. 2006;13(12):1495-9.

13. Kabiri el-H, Caidi M, al Aziz S. Surgical treatment of hydatidothorax. Series of 79 cases. Acta Chir Belg. 2003;103(4):401-4.

14. Zapatero J, Penalver R, Lago J. Pulmonary hydatidosis in childhood. Review of 21 cases. Acta Paediatr Hung. 1991;31(2):241-53. 
15. Balikian JP, Mudarris FF. Hydatid disease of the lungs. A roentgenologic study of 50 cases. Am J Roentgenol Radium Ther Nucl Med. 1974;122(4):692-707.

16. Ozçelik C, Inci I, Toprak M. Surgical treatment of pulmonary hydatidosis in children: experience in 92 patients. J Pediatr Surg. 1994;29(3):392-5.

17. Chaouachi B, Nouri A, Ben Salah S. [Hydatid cyst of the lung in children. Apropos of 643 cases]. Pédiatrie. 1988;43(9):769-73.

18. Thameur H, Chenik S, Abdelmoulah S, Bey M, Hachicha S, Chemingui M, Mestiri T, Chaouch H. Thoracic hydatidosis. A review of 1619 cases. Revue de pneumologie clinique. 2000 Feb;56(1):715 .

19. Ramos G, Orduña A, García-Yuste M. Hydatid cyst of the lung: diagnosis and treatment. World $\mathbf{J}$ Surg. 2001;25(1):46-57.

20. Lewall DB, McCorkell SJ. Rupture of echinococcal cysts: diagnosis, classification, and clinical implications. AJR Am J Roentgenol. 1986;146(2):391-4.

21. Wattre P, Capron M, Bekhti A, Capron A. The immunological diagnosis of hydatidosis. 139 cases (author's transl). La Nouvelle presse medicale. 1980 Jan;9(5):305-9.

22. Khannous M, Ferretti G, Ranchoup Y, Thony F, Robert F, Coulomb M. Intrathoracic hydatid cyst. Contribution of tomodensitometry. Apropos of 25 cases. Journal de radiologie. 1993 Nov;74(11):5418.

23. Racil H, Amar JB, Moulay RE, Ridene I, Cheikrouhou S, Zarrouk M, Chaouch N, Chabbou A. Kystes hydatiques compliqués du poumon. Revue des maladies respiratoires. 2009 Sep 1;26(7):727-34.
24. Hafsa C, Belguith M, Golli M, Rachdi H, Kriaa S, Elamri A, Said M, Brahem R, Zakhama A, Nouri A, Gannouni A. Imaging of pulmonary hydatid cyst in children. Journal de radiologie. 2005 Apr;86(4):405-10.

25. Kuzucu A, Soysal Ö, Özgel M, Yologlu S. Complicated hydatid cysts of the lung: clinical and therapeutic issues. The Annals of thoracic surgery. 2004 Apr 1;77(4):1200-4.

26. Ozvaran MK, Ersoy Y, Uskul B, Unver E, Yalcin E, Baran R, Morice RC. Pleural complications of pulmonary hydatid disease. Respirology. 2004 Mar;9(1):115-9.

27. Shalabi RI, Ayed AK, Amin M. 15 Years in surgical management of pulmonary hydatidosis. Ann Thorac Cardiovasc Surg Off J Assoc Thorac Cardiovasc Surg Asia. 2002;8(3):131-4.

28. Budke CM, Carabin H, Ndimubanzi PC, Nguyen H, Rainwater E, Dickey M, Bhattarai R, Zeziulin $\mathrm{O}$, Qian MB. A systematic review of the literature on cystic echinococcosis frequency worldwide and its associated clinical manifestations. The American journal of tropical medicine and hygiene. 2013 Jun 5;88(6):1011-27.

29. Zaghba N, Benjelloun H, Yassine N. Apport de la sérologie hydatique dans le diagnostic positif de l'hydatidose thoracique. Revue des Maladies Respiratoires. 2018 Jan 1;35:A240.

30. Khalfallah AB, Slima HB. Le kyste hydatique du cœur. Quelle modalité d'imagerie pour un diagnostic précis?. InAnnales de Cardiologie et d'Angéiologie 2017 Apr 1 (Vol. 66, No. 2, pp. 102108). Elsevier Masson.

31. Bouassida I, Pricopi C, Mangiameli G, Arame A, Auliac JB, Gorbatai B. Le Pimpec Barthes Compression cardiaque d'origine hydatique Rev de pneumologie Clinique. 2018; 74:248-252. 